\title{
Detection of Chlorine Gas Using Embedded Piezoresistive Microcantilever Sensors
}

\author{
Timothy L. Porter*, T. Vail ${ }^{1}$, A. Wooley ${ }^{1}$ and Richard J. Venedam ${ }^{2}$ \\ Northern Arizona University, Dept. of Physics, Flagstaff, AZ 86011, USA \\ ${ }^{1}$ Northern Arizona University, Dept. of Chemistry, Flagstaff, AZ 86011, USA \\ ${ }^{2}$ National Security Technologies, Las Vegas, NV, 89193, USA
}

(Received October 1, 2008; accepted October 14, 2009)

Key words: chlorine, microcantilever, embedded

Embedded piezoresistive microcantilever (EPM) sensors may be constructed for various sensing applications. In each application, a custom sensing material that responds volumetrically to the desired analyte is designed. Here, we constructed EPM sensors for chlorine gas $\left(\mathrm{Cl}_{2}\right)$ detection. The sensing materials used consisted of polymer matrices combined with NaI crystals. Sensors constructed from a silicone-based matrix exhibited the strongest response to $\mathrm{Cl}_{2}$, with detection limits in an outdoor exposure setting of approximately $20 \mathrm{ppm}$.

\section{Introduction}

Chlorine gas $\left(\mathrm{Cl}_{2}\right)$ is a yellowish-green gas that may be recognized by its pungent odor similar to that of bleach. Under pressure and with cooling, the gas may be liquefied for transport and storage. When released at atmospheric pressure, it quickly reverts to being gaseous, forming clouds of heavy $\mathrm{Cl}_{2}$ gas that remain low to the ground. $\mathrm{Cl}_{2}$ gas is a pulmonary irritant that exhibits intermediate water solubility. Upon inhalation, this solubility leads to acute damage in the upper and lower respiratory tracts. $\mathrm{Cl}_{2}$ was first used as a chemical weapon in Ypres, France, in 1915.(1) In 2007, Al Qaeda in Iraq conducted a three-pronged suicide car bomb attack using chlorine gas in Anbar province. Suicide truck bombers armed with chlorine gas struck at targets in the cities of Ramadi, Amiriya, and Fallujah, resulting in 3 deaths and over 300 injured.

When chlorine gas reacts with water, both hydrochloric acid $(\mathrm{HCl})$ and hypochlorous acid $(\mathrm{HOCl})$ are formed. Upon exposure of mammals to this gas, inflammation of the conjunctivae, nose, pharynx, larynx, trachea, and bronchi may occur. In animal studies of chlorine gas exposure, immediate respiratory arrest occurs at 2,000 ppm, with the lethal concentration for a $50 \%$ mortality rate of exposed animals occurring in the range of $800-1,000 \mathrm{ppm}$. In a study of anaesthetized and mechanically ventilated pigs, for example, exposures to as low as $140 \mathrm{ppm} \mathrm{Cl}_{2}$ resulted in death in $6 \mathrm{~h}^{(2)}$ For exposure in humans, symptoms that may occur include coughing, chest tightness, burning in the

*Corresponding author: e-mail: Tim.Porter@nau.edu 
chest and lungs, blurred vision, nausea, vomiting, difficulty in breathing, and pulmonary edema.

In this paper, we report on the detection of chlorine gas using embedded piezoresistive microcantilever (EPM) sensors. EPM sensors provide a simple, low-cost, and effective platform for detecting many different types of analyte. In the basic EPM sensor design, a piezoresistive microcantilever is embedded or partially embedded in a sensing material (or in some cases, resting atop the sensing material). ${ }^{(3,4)}$ The sensing material is typically a polymer, a composite polymer, a biological material or any other material that acts as a probe for the desired analyte. ${ }^{(5)}$ When exposed to an analyte, chemical, physical or other reactions with the sensor material result in a volumetric change in the sensing material, which results in the bending of the cantilever. This bending is measured as a simple resistance change by the sensor electronics. The change in the sensing material volume (or dimensions) may be due to several possible mechanisms, including the diffusion of analyte molecules into the sensing material, the probe-target binding on the material surface or bulk, and the surface or bulk chemical reactions between the analyte and the sensing material. Microcantilever strains of only a few angstroms are potentially measurable. Electronics for EPM sensors are simple, because only cantilever resistance is measured during a sensing event. Typically, we use a bridge circuit with a precision A-D converter for our measurements. We have used EPM sensors in a variety of sensing applications, including the sensing of animal presence, ${ }^{(6)}$ hydrogen fluoride gas, ${ }^{(7)}$ organophosphate gases ${ }^{(5,8,9)}$ volatile organic compounds (VOCs), carbon monoxide gas, ${ }^{(10)}$ hydrogen cyanide gas, ${ }^{(11)}$ and others. ${ }^{(12-15)}$

\section{Materials and Methods}

The piezoresistive microcantilevers used in these experiments were designed by Cantimer, Inc., Menlo Park, CA. The microcantilevers are approximately $200 \mu \mathrm{m}$ long and $40 \mu \mathrm{m}$ wide, each contained in a silicon die chip. Each cantilever extends into a small circular area on each chip to contain the sensing material and also protect the cantilever during sensor assembly. An integrated thermistor to be used for temperature correction is also integrated into each die for applications where temperature information of correction is needed. ${ }^{(7)}$ Each sensor is fabricated by dispensing a measured amount of sensing material at the edge of a Si substrate. Although the sensing material is still in liquid phase (or soft), the microcantilever tip is positioned to insert into the material, or in some cases only to make contact with the material. The substrate is then bonded to the chip using epoxy. The nominal resistance of the bare cantilevers before assembly is approximately $2.2 \mathrm{k} \Omega$. During drying or curing, the sensor resistance will typically change by about $50 \Omega$, indicating that the cantilever is being bent or prestrained by a small amount.

For chlorine gas detection, we chose sensing materials consisting of polymer matrices combined with crystals of sodium iodide (NaI). The polymers used were Hypol, a hydrogel material supplied by Dow Chemical, and a more common silicone-based polymer used in window caulking applications (commercially available under many different brand names). In each case, NaI was loaded into the polymer host material at 
$30 \%$ by weight. In the case of Hypol, exposure to ambient air after mixing in $\mathrm{NaI}$ was sufficient to form a foam-like gel within only 10-20 min. Microcantilever tip insertion into the sensing material was accomplished within $30 \mathrm{~min}$ of exposure to air. For the silicone matrix, tip insertion was accomplished $30 \mathrm{~min}$ after mixing or later, and the assembly was allowed to set at room temperature for $24 \mathrm{~h}$ or more before use.

For the laboratory segments of this study, we used a single-chip AD7793 24-bit A-D converter that functions as a $6 \frac{1}{2}$ digit multimeter to directly measure cantilever resistance using two leads. The AD7792 chip is interfaced to a laptop computer through a USB interface provided by a USBmicro 421 chip. Data collection is performed using a laptop computer using LabView (National Instruments, Austin, TX). ${ }^{(16)}$ For experiments in open air, we used a small bridge circuit interfaced to a battery-powered mote to send signals back to our host gateway laptop computer. ${ }^{(17)}$ This setup enabled us to deploy numerous microcantilever-based sensors in a remote, wireless mesh configuration when needed. Here, only two of the motes were used. For the data shown in this paper, no filtering or smoothing was performed in any of the charts shown.

Laboratory testing of the sensors was performed in a chamber of approximately 3.51 . $\mathrm{Cl}_{2}$ gas was added in controlled amounts so that exposure levels could be precisely determined. Outdoor exposure was performed at the DOE Nevada Test Site Non-Proliferation Test and Evaluation Center (NPTec). Chlorine gas was released through portable stacks from gas bottles in a controlled release lasting 15-30 min. The EPM sensors interfaced to radio motes were positioned $80 \mathrm{~m}$ downwind from the release points. The exact exposure levels are not known, but they can be estimated by comparison from our controlled laboratory experiments.

\section{Results and Discussion}

EPM sensor exposure to high $\mathrm{Cl}_{2}$ levels was performed in the laboratory. Here, the exposure level was calculated to be 1,000 ppm. In Fig. 1, the responses from both the Hypol-NaI and the silicone-NaI sensors are shown. Arrows on the charts indicate the time of the initial exposure. Also, in both cases, the exposure at 1,000 ppm was maintained in the test chamber for approximately $15 \mathrm{~min}$. The initial sensor response for both sensing materials was virtually immediate, occurring within $5 \mathrm{~s}$ of the initial exposure. Also, the sensor response continued to increase throughout the exposure period for both sensors. Over the 15-min exposure period, the total response from the Hypol-based sensor was $1.6 \mathrm{mV}$, whereas that from the silicone-based sensor was $2.1 \mathrm{mV}$. For these EPM sensors, the cantilever sensitivity to deflection (with a fixed current of $210 \mu \mathrm{V}$ passing through the cantilever) is approximately $1 \mathrm{mV}$ per micron of deflection. Thus, for the $1,000 \mathrm{ppm}$ exposure, we calculate the cantilever deflection to be $1.6 \mu \mathrm{m}$ for the Hypol-based sensor and $2.1 \mu \mathrm{m}$ for the silicone-based sensor. The chemical reaction of $\mathrm{NaI}$ with $\mathrm{Cl}_{2}$ is: $2 \mathrm{NaI}+\mathrm{Cl}_{2} \rightarrow 2 \mathrm{NaCl}+\mathrm{I}_{2}$. We believe that this reaction proceeds immediately with $\mathrm{NaI}$ in the surface regions of the composite sensing material, and continues reacting into deeper layers of the material as the reaction proceeds. Since the preloaded cantilever deflection is known for these sensors, we also conclude that the reaction is causing the sensing material volume to decrease slightly 


\section{Hypol, 1000 ppm}

(a)

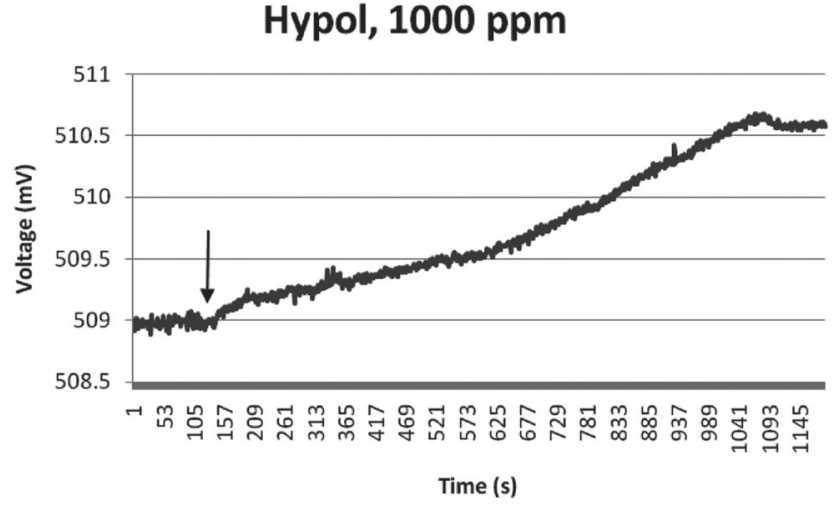

Silicone, 1000 ppm

(b)

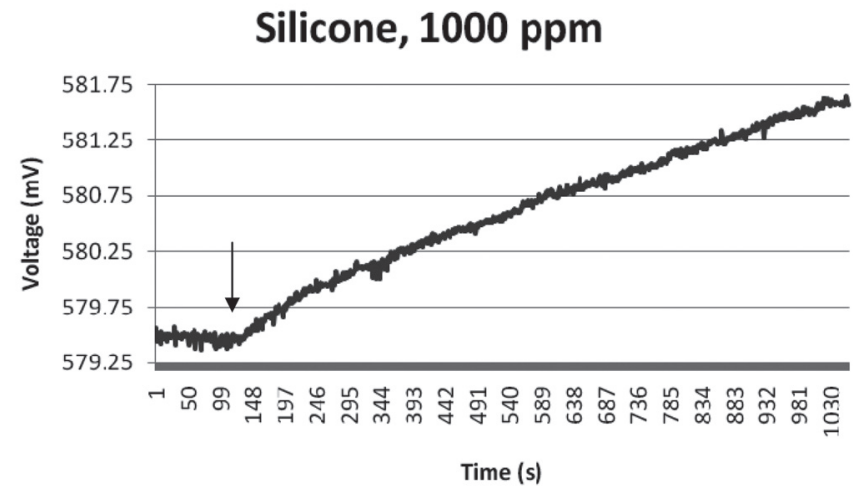

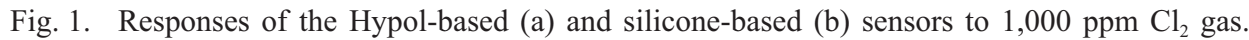
The cantilever response of the Hypol-based sensor is $1.6 \mu \mathrm{m}$, whereas that of the silicone-based sensor is $2.1 \mu \mathrm{m}$.

throughout the reaction. The reaction of the sensing material with $\mathrm{Cl}_{2}$ gas is irreversible, that is, once the sensing material has completely reacted with the gas, the sensor is rendered inoperable.

In Fig. 2, the response of two new sensors to lower levels of $\mathrm{Cl}_{2}$ is shown. For this exposure, the $\mathrm{Cl}_{2}$ level was set to $100 \mathrm{ppm}$. Arrows indicate the time of the initial exposure to the gas. As in the previous charts, the raw data is shown with no filtering or smoothing. From these charts, we see that the Hypol-based sensor response is minimal, which is near the signal-to-noise threshold for detection (some improvement may be realized with filtering, however). The sensor voltage change is approximately $0.1 \mathrm{mV}$, corresponding to a cantilever deflection of $0.1 \mu \mathrm{m}$. For the silicone-based sensor, the total sensor response is larger, approximately $0.2 \mathrm{mV}$, corresponding to a cantilever deflection of $0.2 \mu \mathrm{m}$. In the case of the silicone-based sensor, the total sensor response to the $100 \mathrm{ppm}$ exposure is approximately one-tenth of the response of the same sensing material to a 1,000 ppm exposure. For the Hypol-based sensor, the total sensor 
(a)

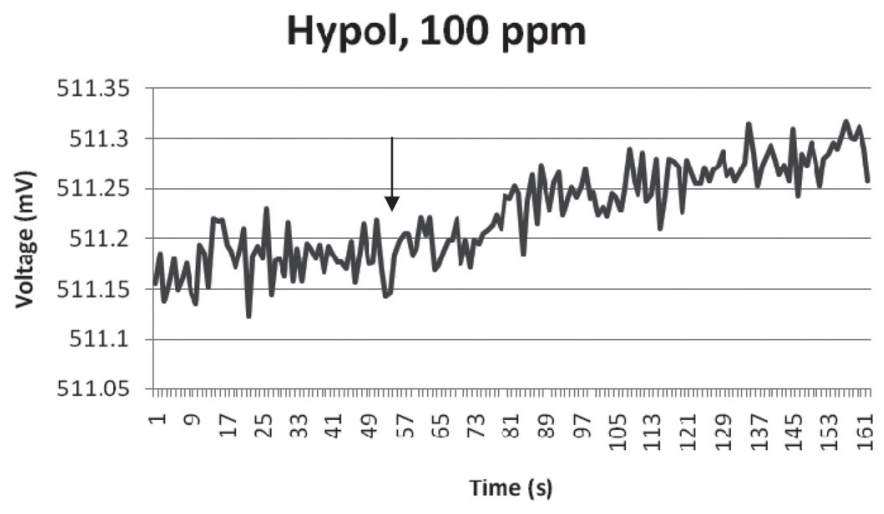

\section{Silicone, 100 ppm}

(b)

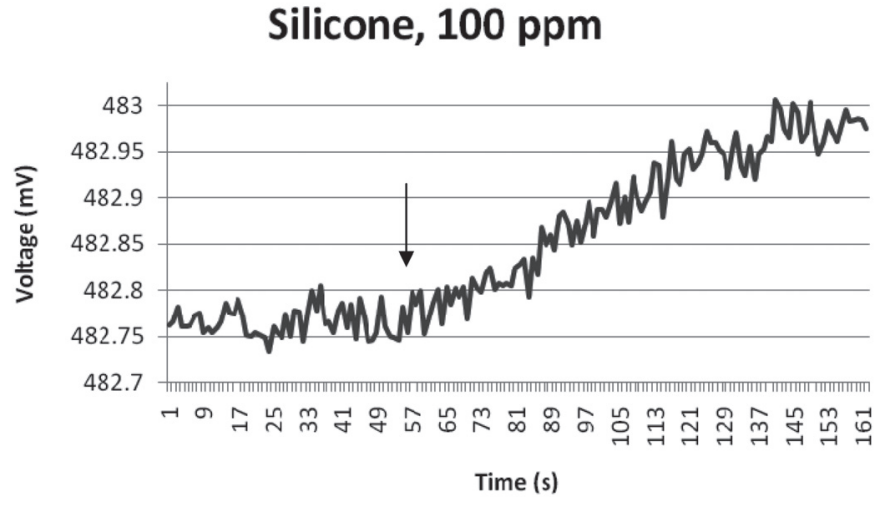

Fig. 2. Similar Hypol and silicone-based sensors exposed to $100 \mathrm{ppm}^{\mathrm{Cl}_{2}}$ gas in a controlled laboratory setting. At these lower exposure levels, the cantilever responses were 0.1 and $0.2 \mu \mathrm{m}$, respectively.

response to the $100 \mathrm{ppm}$ exposure is 0.0625 of the $1,000 \mathrm{ppm}$ exposure. Despite the small differences in the linearity of the two types of sensors, the silicone-based sensors clearly exhibit greater sensitivity to $\mathrm{Cl}_{2}$. In both types of sensor, the overall thickness of the sensing material was kept as close to the same as our assembly procedure would allow. Optical microscopy shows the sensing material thicknesses to be within $5 \%$ of each other. Also, the mechanical mixing of the $\mathrm{NaI}$ crystals into the polymer matrix was the same in both cases. Inspection of the finished materials did not indicate any unusual clumping or aggregation of the $\mathrm{NaI}$ in either of the two polymer matrices. We believe that the sensitivity difference between the two types of sensing materials arises primarily from the differing mechanical properties of the two polymer host materials. After roomtemperature curing, the Hypol-based material was foam-like in structure, with tiny, microscopic pockets of trapped air throughout the material. This is typical for Hypol to form this foam-like gel when curing in air. It may be that these microscopic pockets of air partially trap or otherwise impede the diffusion of $\mathrm{Cl}_{2}$ into the material over time, 


\section{Silicone, NTS}

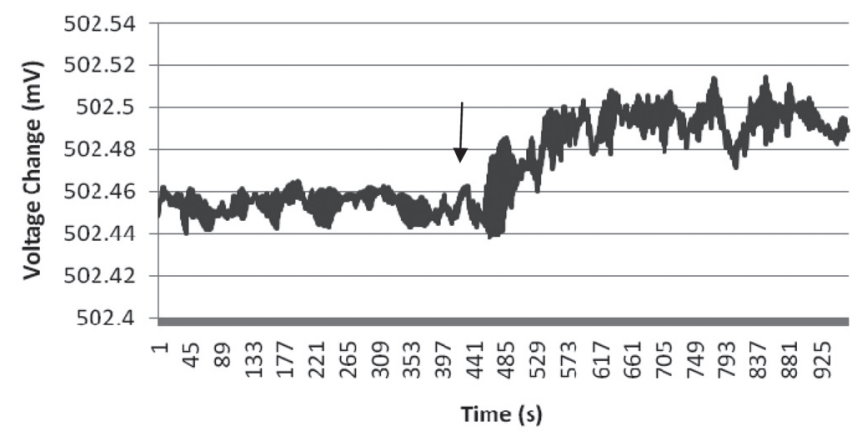

Fig. 3. Response of silicone-based EPM sensor to low $\mathrm{Cl}_{2}$ gas levels in an outdoor setting. On the basis of previous response levels for the silicone-based sensor, we estimate the $\mathrm{Cl}_{2}$ level to be approximately $25 \mathrm{ppm}$.

resulting in a lower overall response to the analyte. Future experiments using this host polymer material will further explore how the physical structure of Hypol affects the sensor response to various analytes.

Owing to the overall stronger response of the silicone-based sensors than of the Hypol-based sensors, we constructed a new silicone-based NaI composite sensor for outdoor testing at the Nevada Test Site NPTec facility. The sensor itself was identical to those used in the laboratory setting, but was interfaced to a laptop computer through a radio mote for remote sensing applications. In Fig. 3, a $1 \mathrm{~h}$ time interval centered on the release time is shown. Here, $\mathrm{Cl}_{2}$ gas was released from a tank through an elevated stack into the open. The release itself spanned a time interval of 15 to $30 \mathrm{~min}$. The sensor was located $80 \mathrm{~m}$ downwind from the release stack, and subject to small variations in wind speed and wind direction. The temperature remained nearly constant throughout this period, but there was a slight linear temperature drift (about $0.2^{\circ} \mathrm{C}$ ) that was subtracted from the data. Overall, the wind speed was within approximately $10-15 \mathrm{mph}$ during the test. From Fig. 3, we see that the overall sensor response is very small. This digitally filtered signal indicated a total sensor response of approximately $0.04 \mathrm{mV}$, for a cantilever displacement of $0.04 \mu \mathrm{m}$. If we compare this signal with that of the same silicone-based sensor responses at 1,000 ppm and $100 \mathrm{ppm}$, we can state that this sensor receives an exposure of approximately $20 \mathrm{ppm}$ over the release period. This small signal is probably near the limits of detection for the EPM sensor with the sensing material that we are using in these tests.

\section{Conclusion}

Chlorine gas detectors may be successfully constructed using the EPM sensor design with a sensing material based on a polymer matrix combined with $\mathrm{NaI}$ crystals $(30 \%$ by weight). In our tests, silicone-based sensors showed better sensitivity to $\mathrm{Cl}_{2}$ exposure (about 
$30 \%$ better sensitivity), and stronger linearity when exposed to smaller amounts of the gas. On the basis of our data, detection limits of approximately $20 \mathrm{ppm}$ may be obtained in an outdoor exposure environment. We also developed sensing materials using the same polymer matrices, with larger percentages of $\mathrm{NaI}$ incorporated in them. These resulted in materials that were generally more difficult to handle, and more difficult to incorporate in the EPM sensor design.

\section{Acknowledgement}

We would like to thank the staff of the DOE Nevada Test Site NPTec facility for their excellent support and cooperation in all these tests.

\section{References}

1 in New York Tribune (1915).

2 M. Gunnarsson, S. M. Walther, T. Seidal, G. D. Bloom and S. Lennquist: J. Appl. Toxicology 18 (1998) 249.

3 T. L. Porter, W. Delinger and R. L. Gunter: Proc. Materials Research Soc. (2005).

4 T. L. Porter, M. P. Eastman, C. Macomber, W. G. Delinger and R. Zhine: Ultramicroscopy 97 (2003) 365 .

5 T. L. Porter, M. P. Eastman, D. L. Pace and M. Bradley: Scanning 22 (2000) 1.

6 T. L. Porter, T. R. Dillingham and R. J. Venedam: Appl. Herpetology (in press).

7 T. L. Porter, T. Vail, J. Reed and R. Stewart: Sensors and Materials 20 (2008) 103.

8 T. L. Porter, T. Vail and R. Venedam: Proc. Materials Research Soc. 1086E (2008) 1086-u08-02.

9 C. S. Macomber, M. P. Eastman, T. L. Porter, K. Manygoats and W. Delinger: J. Electrochem. Soc. 150 (2003) 1.

10 A. Kooser, R. L. Gunter, W. G. Delinger, T. L. Porter and M. P. Eastman: Sens. Actuators, B 99 (2004) 430.

11 T. L. Porter, T. Vail, M. P. Eastman, R. Stewart, J. Reed, R. Venedam and W. Delinger: Sens. Actuators, B 123 (2007) 313.

12 R. L. Gunter, W. Delinger, T. L. Porter, R. Stewart and J. Reed: Med. Eng. Phys. 27 (2005) 215.

13 R. L. Gunter, W. G. Delinger, K. Manygoats, A. Kooser and T. L. Porter: Sens. Actuators, A 107 (2003) 219.

14 A. Kooser, K. Manygoats, M. P. Eastman and T. L. Porter: Biosens. Bioelectron. 19 (2003) 503.

15 T. L. Porter, W. Delinger, A. Kooser, K. Manygoats and R. Gunter: Sens. Actuators, A 107 (2003) 219.

16 T. L. Porter and W. Delinger: Sensors and Transducers 68 (2006) 568.

17 T. L. Porter, W. Delinger and R. Venedam: Sensors and Transducers (in press). 